\title{
PEMANFAATAN LIMBAH PADAT INDUSTRI PENYAMAKAN KULIT (SHAVING) UNTUK PAPAN PARTIKEL POLYVINYL CHLORIDA
}

\section{(THE UTILIZATION OF SOLID WASTE OF LEATHER TANNING INDUSTRY (SHAVING) FOR POLYVINYL CHLORIDE PARTICLE BOARD)}

\author{
Supraptiningsih ${ }^{1)}$ \\ Email: ningsih1957@yahoo.com \\ Diterima: 25 Januari 2011 \\ Disetujui: 28 Mei 2012
}

\begin{abstract}
The aim of this research was to study the effect of solid waste of leather tanning industry (shaving) to physical properties of PVC particle board. Particle board was produced from PVC, additives material and solid waste of leather tanning industry (shaving). The variation of solid waste (shaving) content are 0; 10; 20; 30; 40; 50; 60; and 70 phr respectively. The compound was made by mixer and two roll mill unheated, mixing by torque speed $30 \mathrm{rpm}$. Press condition are $165^{\circ} \mathrm{C}, 150 \mathrm{~kg} / \mathrm{cm}^{2}$, and it needs 6 minutes for $2 \mathrm{~mm}$ thickness and 30 minutes for $10 \mathrm{~mm}$ thickness (depend on kinds of test). The particle board was tested physical properties by methods of SNI 03-2105-2006 Mutu Papan Partikel. The test result of physical properties showed that solid waste of leather tanning industry for particle board was significant enfluence to increased tensile strength, water contains, thickness swelling, but decreased screw withdrawl and flexibility. Solid waste of leather tanning industry (shaving) added was not significant influence to density.
\end{abstract}

Keywords: particle boards, polyvinyl chloride, shaving learther, physical properties

\begin{abstract}
ABSTRAK
Tujuan penelitian ini adalah mempelajari pengaruh penambahan limbah padat IPK (shaving) terhadap sifat fisis papan partikel dari PVC. Papan partikel dibuat dari bahan plastik polivinil chlorida dan bahan pembantu serta limbah padat IPK (shaving). Penelitian dilakukan dengan memvariasikan jumlah limbah padat IPK (shaving) yaitu $0 ; 10 ; 20 ; 30 ; 40 ; 50 ; 60 ;$ dan 70 phr. Pencampuran dilakukan dalam mixer, dan alat two roll mill tanpa panas, diputar dengan kecepatan putar torsi $30 \mathrm{rpm}$. Kondisi pengepresan adalah: suhu $165^{\circ} \mathrm{C}$, tekanan $150 \mathrm{~kg} / \mathrm{cm}^{2}$, waktu 6 menit untuk tebal $2 \mathrm{~mm}$ dan 30 menit untuk tebal $10 \mathrm{~mm}$ (tergantung jenis uji). Papan partikel yang diperoleh diuji sesuai SNI 03-2105-2006 Mutu Papan Partikel. Hasil pengujian sifat fisis menunjukkan bahwa limbah padat IPK (shaving) pada kompon polyvinyl chloride untuk papan partikel, berpengaruh nyata menaikkan sifat kuat tarik, kadar air, pengembangan tebal, tapi menurunkan sifat kuat pegang sekrup, dan kuat lentur. Penambahan limbah padat IPK (shaving) tidak berpengaruh nyata pada sifat kerapatan massa.
\end{abstract}

Kata Kunci: papan partikel, polyvinyl chloride, limbah padat IPK (shaving), sifat fisis

\section{PENDAHULUAN}

Industri penyamakan kulit merupakan industri yang sangat potensial menghasilkan limbah yang mengganggu lingkungan.
Limbah yang dihasilkan berupa limbah padat, cair, dan gas yang apabila tidak ditangani dengan baik, maka akan mencemari lingkungan di sekitarnya. Limbah padat dapat

${ }^{1)}$ Balai Besar Kulit, Karet dan Plastik, Yogyakarta 
Dihasilkan dari proses shaving berupa potongan-potongan kecil kulit dan dari proses buffing yang berupa debu. Kedua limbah tersebut mengandung krom, sehingga apabila dibuang begitu saja akan mencemari tanah tempat pembuangan limbah tersebut. Oleh karena itu perlu diupayakan penanganannya atau bahkan pemanfaatannya agar limbah tersebut dapat mempunyai nilai tambah.

Beberapa penelitian yang telah dilakukan terhadap limbah padat industri penyamakan kulit (shaving) adalah pemanfaatan untuk pembuatan kompon sol karet, pembuatan kertas, dan lain-lain. Pada penelitian ini limbah padat industri penyamakan kulit (shaving) akan dimanfaatkan untuk pembuatan papan partikel dari bahan Polyvinyl Chloride (PVC). Penggunaan limbah padat industri penyamakan kulit (shaving) divariasikan jumlahnya agar dapat diketahui penggunaan maksimum, dengan kualitas produk yang mempunyai sifat fisis terbaik. Tujuan dari penelitian ini adalah untuk mengetahui pengaruh jumlah limbah padat industri penyamakan kulit (shaving) terhadap sifat fisis papan partikel dari Polyvinyl Chloride serta mencari formulasi kompon papan partikel yang memenuhi persyaratan SNI 032105-2006 Mutu Papan Partikel.

Industri papan partikel merupakan salah satu usaha yang memanfaatkan kayu yang berkualitas rendah atau limbah industri kayu, sehingga harga dapat ditekan. Selain sebagai penyekat ruang, papan partikel dapat digunakan untuk mebel dan bahan bangunan, yaitu: meja, kursi, almari, plafon, pintu, dan lain-lain. Beberapa jenis penyekat ruang/partisi yang ada di pasaran antara lain: papan partikel, hardboard, papan serat, papan blok, kayu lapis, dan lembaran serat semen. Papan partikel dibuat dari kayu atau pemanfaatan limbah potongan-potongan kayu sebagai bahan baku, dengan penambahan bahan perekat urea formadehide dan phenol formaldehyde. Berbagai macam bahan dapat digunakan untuk membuat papan partikel yaitu: kayu, limbah kayu, atau plastik, yang masing-masing mempunyai kelebihan dan kekurangan Papan partikel/komposit dari campuran kayu dan plastik disebut juga komposit plastik. Bahan komposit plastik merupakan bahan bangunan tiruan yang dibuat dari campuran serat kayu (bahan organik) dan bahan perekat dari plastik. Pada perbandingan tertentu, melalui proses tekan dan panas dapat mempunyai sifat tehnis dan penampakan yang baik sehingga dapat digunakan sebagai bahan bangunan (Lasino dan Kusmara, 2000).

Papan partikel cenderung lebih berat dari kebanyakan material kayu lainnya, memiliki kekuatan pengikat yang lemah dan cenderung mudah remuk di ujungnya apabila diperlakukan dengan kasar. Beberapa penelitian dilakukan untuk membuat papan partikel yang cenderung stabil dan tidak mudah berubah bentuknya (menyusut, membelok, dan lain lain). Papan partikel juga dapat dipotong, dibentuk, dan dibor dengan mudah. Papan untai (Oriented Strand Board atau OSB) merupakan salah satu jenis penyekat yang dibuat dari partikel berbentuk untai (strand), berlapis tiga dengan arah serat lapisan luar tegak lurus dengan lapisan tengah memiliki sifat sama dengan kayu sehingga dapat menggantikan fungsi kayu lapis ( Blomquist dkk, 1983 dan Blinn dkk, 1986). Mata rantai menggambarkan keteguhan permukaan kayu (prinsip kohesi dari bahan yang direkat), dan menggambarkan ikatan permukaan kayu dengan perekat (prinsip adhesi) (Sutrisno dkk, 2000).

Kebutuhan kayu yang terus meningkat dan potensi hutan yang terus berkurang menuntut penggunaan kayu secara efisien dan bijaksana. Telah dilakukan penelitian di Universitas Sumatera Utara dan Institut Pertanian Bogor pada Agustus-September 2009 yaitu membuat papan plastik komposit dari variasi jenis plastik low-density polyethylene (LDPE), polypropylene (PP), dan polystyrene (PS) daur ulang dan limbah serbuk kayu yang direndam dan tidak direndam. Papan partikel yang akan dibuat pada penelitian ini adalah campuran limbah padat industri penyamakan kulit (shaving) dengan bahan perekat plastik PVC.

\section{BAHAN DAN METODE PENELITIAN Bahan penelitian}

Bahan baku yang digunakan dalam penelitian ini adalah polyvinyl chloride (PVC) 
bentuk powder yang dibeli dari pasaran, limbah padat industri penyamakan kulit (shaving) dari Laboratorium Penyamakan Kulit, Siti Mulyo, Piyungan, Yogyakarta. Bahan penolong yang digunakan adalah dioctyl phtalat sebagai plasticizer, heat stabilizer, asam stearat, $\mathrm{CaCO}_{3}$ sebagai filler, epoxy plasticizer oil, dan zat warna.

\section{Alat penelitian}

Alat yang digunakan untuk penelitian ini adalah, grinder untuk memperhalus ukuran limbah padat industri penyamakan kulit (shaving), mixer, crusser, two roll mill hydraulic press untuk membuat slab, gunting, timbangan, plat besi, wadah-wadah plastik, dan pengaduk plastik. Alat-alat untuk pengujian papan partikel adalah tensile strength tester untuk uji kuat tarik, kuat pegang sekrup, dan kuat lentur. Oven, timbangan, jangka sorong untuk uji kadar air, dan kerapatan massa.

\section{Cara penelitian}

Kompon polivinil chlorida dicampur dengan serbuk limbah kulit shaving menggunakan mixer. Campuran tersebut dimasukkan dalam alat two roll mill tanpa panas, diputar sampai minimal 6 kali agar homogen dengan kecepatan putar torsi 30 rpm.

Kompon yang diperoleh masing-masing di press dengan Hydroulic Press. Kondisi pengepresan kompon polivinil chlorida adalah: suhu $165^{\circ} \mathrm{C}$, tekanan $150 \mathrm{~kg} / \mathrm{cm}^{2}$, waktu 6 menit untuk tebal $2 \mathrm{~mm}$ dan 30 menit untuk tebal $10 \mathrm{~mm}$ (tergantung jenis uji). Hasil pengepresan berupa slab dengan ukuran $15 \mathrm{x}$ $20 \mathrm{~cm}$. Penelitian dilakukan dengan memvariasikan jumlah limbah kulit shaving sesuai rancangan penelitian.

\section{Rancangan Penelitian}

Kompon papan partikel dibuat dari campuran bahan baku dan bahan penolong. Variasi jumlah limbah kulit shaving adalah $0 ; 10 ; 20 ; 30 ; 40 ; 50 ; 60$; dan 70 phr. Penggunaan bahan penolong untuk kompon polivinil chlorida adalah dioctyl pthalat (30 phr), stabilizer ( $3 \mathrm{phr}$ ), epoxy oil ( $5 \mathrm{phr}$ ), dan asam stearat (1phr). Formulasi kompon yang dibuat disajikan pada Tabel 1.

Tabel 1. Formulasi kompon papan partikel.

\begin{tabular}{|l|c|c|c|c|c|c|c|c|}
\hline \multicolumn{1}{|c|}{ Bahan (phr) } & \multicolumn{9}{c|}{ Formula } \\
\hline & & & & & & & & \\
PVC & 100 & 100 & 100 & 100 & 100 & 100 & 100 & 100 \\
Limbah kulit shaving & 0 & 10 & 20 & 30 & 40 & 50 & 60 & 70 \\
Dioctyl phtalat & 30 & 30 & 30 & 30 & 30 & 30 & 30 & 30 \\
Stabilizer & 3 & 3 & 3 & 3 & 3 & 3 & 3 & 3 \\
Epoxy Oil & 5 & 5 & 5 & 5 & 5 & 5 & 5 & 5 \\
Asam stearat & 1 & 1 & 1 & 1 & 1 & 1 & 1 & 1 \\
& & & & & & & & \\
\hline
\end{tabular}

Pengujian yang dilakukan terhadap papan partikel hasil penelitian meliputi uji kuat tarik, uji kuat pegang sekrup, uji kuat lentur, uji kadar air, dan uji kerapatan sesuai persyaratan pada SNI 03-2105-2006 Mutu Papan Partikel.

\section{Analisis Data}

Data hasil pengujian sifat fisis dianalisis faktorial desain. Hasil perhitungan statistik berupa tabel Anova yang digunakan sebagai acuan pembahasan untuk dapat mengetahui pengaruh jumlah limbah padat industri penyamakan kulit (shaving) terhadap sifat fisis papan partikel dari polivinil chlorida. Pertimbangan untuk papan partikel terbaik berdasarkan jumlah limbah kulit shaving terbanyak yang dapat disubstitusikan dalam 
kompon dengan hasil tetap memenuhi persyaratan standar SNI 03-2105-2006 Mutu Papan Partikel.

\section{HASIL DAN PEMBAHASAN}

Hasil penelitian berupa data hasil uji sifat fisis papan partikel meliputi uji kuat tarik, uji kuat pegang sekrup, uji kuat lentur, uji kadar air, dan uji kerapatan. Hasil uji sifat fisis kompon papan partikel disajikan dalam Tabel 2. Pembahasan dilakukan untuk mengamati pengaruh jumlah limbah kulit shaving terhadap masing-masing sifat fisis papan partikel dari polivinil chlorida.

\section{Pengaruh jumlah limbah kulit shaving pada sifat kuat tarik.}

Hasil uji kuat tarik papan partikel pada berbagai variasi jumlah limbah kulit shaving disajikan pada Gambar 1.

Gambar 1 menunjukkan bahwa penambahan limbah padat industri penyamakan kulit (shaving) cenderung menaikkan nilai kuat tarik lurus permukaan pada papan partikel PVC secara significant. Pada papan partikel PVC tanpa penambahan limbah kulit shaving nilai kuat tarik telah memenuhi persyaratan SNI 03-2105-2006 Mutu Papan Partikel.

Makin banyak limbah kulit shaving yang ditambahkan menaikkan nilai kuat tarik. Hal ini disebabkan karena limbah kulit shaving dapat berfungsi sebagai bahan pengisi/filler yang bersifat reinforcement/penguat pada papan partikel.

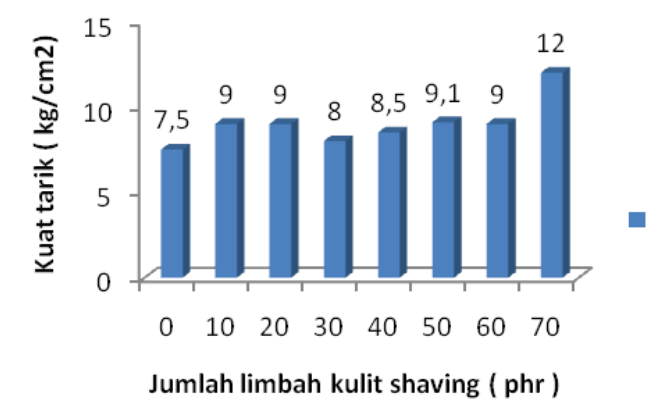

Gambar 1. Kuat tarik papan partikel PVC dengan limbah kulit shaving.
Molekul-molekul karbon pada rantai atom dapat berikatan dengan molekul pada limbah padat (dalam hal ini limbah kulit shaving) dengan gaya van der waals sehingga membuat kompon plastik makin kuat yang ditunjukkan dengan nilai kuat tarik yang tinggi (Gupta, 1983). Nilai tertinggi dicapai dengan penambahan limbah kulit shaving 70 phr yang berbeda nyata dengan yang lainnya. Semua papan partikel hasil penelitian memenuhi persyaratan standar yang mensyaratkan nilai kuat tarik lurus permukaan minimal $3 \mathrm{~kg} / \mathrm{cm}^{2}$.

\section{Pengaruh jumlah limbah kulit shaving pada sifat kuat pegang sekrup}

Hasil uji kuat tarik kompon papan partikel pada berbagai variasi jumlah limbah kulit shaving disajikan pada Gambar 2

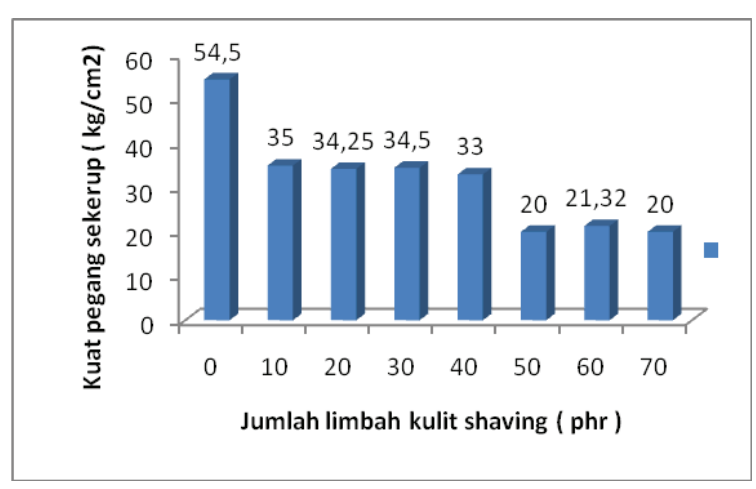

Gambar 2. Kuat pegang sekrup papan partikel PVC dengan limbah kulit shaving

Hasil uji kuat pegang sekrup pada kompon PVC mempunyai kecenderungan menurun, yaitu makin banyak jumlah limbah kulit shaving yang ditambahkan dalam kompon nilai kuat pegang sekrup nilai mengecil. Kompon dengan penambahan limbah kulit shaving sampai 40 phr masih dapat memenuhi persyaratan SNI 03-21052006 Mutu Papan Partikel, yaitu mempunyai nilai kuat pegang sekrup $33 \mathrm{~kg} / \mathrm{cm}^{2}$. Persyaratan standar kuat pegang sekrup minimal $30 \mathrm{~kg} / \mathrm{cm}^{2}$.

Berdasarkan data pada Gambar 2. terlihat bahwa papan partikel hasil penelitian memiliki kuat pegang sekrup paling besar sebesar $35 \mathrm{~kg} / \mathrm{cm} 2$. Nilai tersebut dapat 
tercapai karena papan partikel memilki pergesekan yang kuat dengan alat uji sekrupnya (Subiyanto dkk, 2004). Papan partikel tanpa limbah kulit shaving artinya seluruhnya PVC, mempunyai nilai yang tinggi yaitu $54,5 \mathrm{~kg} / \mathrm{cm}^{2}$. Penambahan limbah kulit shaving menjadikan nilai kuat pegang sekrup menurun. Hal ini disebabkan karena limbah kulit shaving merupakan material berpori, sehingga bila dicampur dengan plastik PVC menyebabkan kompon plastik lebih lunak karena adanya pori-pori tersebut. Kompon yang lebih lunak menyebabkan kuat pegang sekrup turun. Pada papan partikel yang mengandung limbah kulit shaving $70 \mathrm{phr}$ memiliki kuat pegang sekrup paling kecil yaitu sebesar $20 \mathrm{~kg} / \mathrm{cm}^{2}$.

\section{Pengaruh jumlah limbah kulit shaving pada sifat kuat lentur}

Hasil uji kuat tarik kompon papan partikel pada berbagai variasi limbah kulit shaving disajikan pada Gambar 3 .

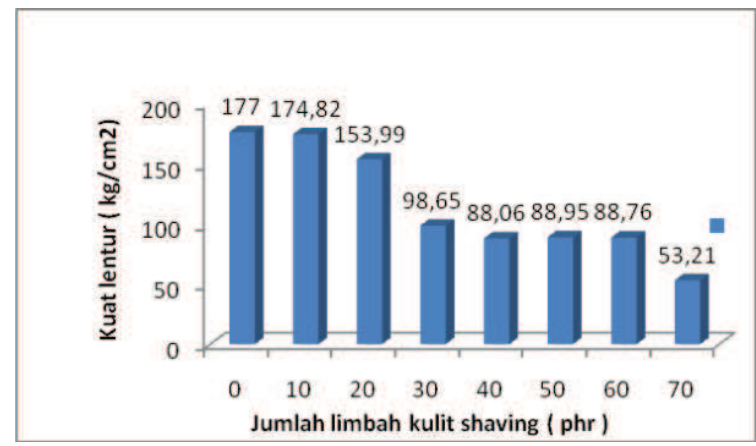

Gambar 3. Kuat lentur papan partikel PVC dengan limbah kulit shaving

Hasil uji kuat lentur papan partikel PVC pada gambar di atas mempunyai kecenderungan menurun, yaitu makin banyak jumlah limbah kulit shaving yang ditambahkan nilai kuat lentur makin kecil. Hal ini disebabkan karena di dalam kompon PVC, limbah kulit shaving dapat berfungsi sebagai filler, sehingga bila ditambahkan ke dalam kompon menyebabkan nilai kuat lentur menurun yang berarti kompon makin rigid (tidak lentur) (Gupta,1983). Semua papan partikel PVC hasil penelitian tidak memenuhi persyaratan SNI 03-2105-2006 Mutu Papan
Partikel, bahkan papan partikel PVC tanpa limbah kulit shaving juga tidak dapat memenuhi persyaratan standar. Hal ini disebabkan oleh sifat PVC yang rigid/kaku, dan bila ditambah limbah shaving akan makin kaku (tidak lentur). Sifat rigid dapat diperbaiki dengan penambahan plasticizer. Pada penelitian ini digunakan plsticizer dioctylpthalat (DOP), yang ternyata jumlah (phr) kurang, sehingga kuat lentur kompon PVC belum memenuhi persyaratan standar, yaitu $177 \mathrm{~kg} / \mathrm{cm}^{2}$ Persyaratan standar adalah minimum $180 \mathrm{~kg} / \mathrm{cm}^{2}$.

\section{Pengaruh jumlah limbah kulit shaving pada sifat kadar air}

Hasil uji kuat tarik kompon papan partikel pada berbagai variasi jumlah limbah kulit shaving disajikan pada Gambar 4.

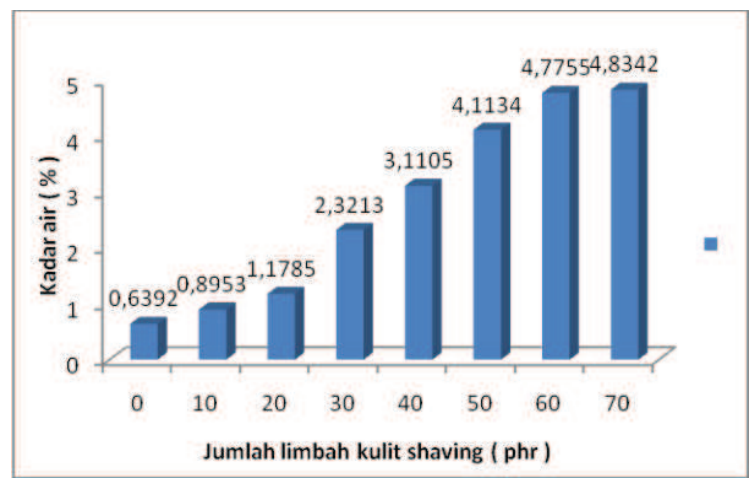

Gambar 4. Kadar air papan partikel PVC dengan limbah kulit shaving

Hasil uji kadar air pada kompon PVC dengan penambahan limbah kulit shaving cenderung naik, yaitu penambahan limbah makin banyak nilai kadar air makin meningkat.

Limbah padat industri penyamakan kulit (shaving) dapat menyerap molekul air, sehingga kompon yang mengandung limbah makin banyak, nilai kadar air meningkat.

Semua kompon hasil penelitian dapat memenuhi persyaratan SNI 03-2105-2006 Mutu Papan Partikel, yaitu nilai berkisar dari 0,6392-4,8342\%, sedangkan standar mensyaratkan nilai maksimal kadar air $14 \%$. 


\section{Pengaruh jumlah limbah kulit shaving pada sifat kerapatan}

Hasil uji kerapatan kompon papan partikel pada berbagai variasi jumlah limbah kulit shaving disajikan pada Gambar 5.

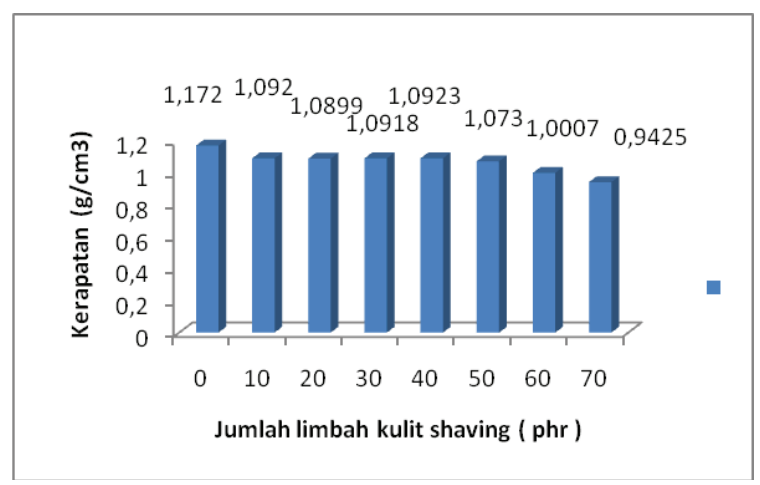

Gambar 5. Kerapatan massa papan partikel PVC dengan limbah kulit shaving

Hasil uji pada Gambar 5. di atas menunjukkan bahwa penambahan limbah padat industri penyamakan kulit (shaving) tidak mempengaruhi kerapatan massa kompon PVC secara significant. Penambahan limbah kulit shaving sampai $50 \mathrm{phr}$ ternyata tidak berpengaruh nyata pada kerapatan massa kompon. Kemungkinan yang terjadi adalah pada kompon PVC tidak banyak limbah padat yang dapat terikat oleh molekul-molekul PVC, sehingga berat kompon menjadi ringan dan kerapatan massa rendah.

Semua kompon hasil penelitian tidak dapat memenuhi persyaratan SNI 03-21052006 Mutu Papan Partikel untuk kerapatan massa yang persyaratan nilainya adalah 0,4 $0,9 \mathrm{~g} / \mathrm{cm}^{2}$.

\section{Pengaruh jumlah limbah kulit shaving pada sifat pengembangan tebal}

Hasil uji pengembangan tebal papan partikel pada berbagai variasi jumlah limbah kulit shaving disajikan pada Gambar 6.

Hasil uji pengembangan tebal yang ditunjukkan pada Gambar 6. tampak bahwa makin banyak limbah padat industri penyamakan kulit (shaving) yang ditambahkan pada papan partikel nilai pengembangan tebal makin besar.

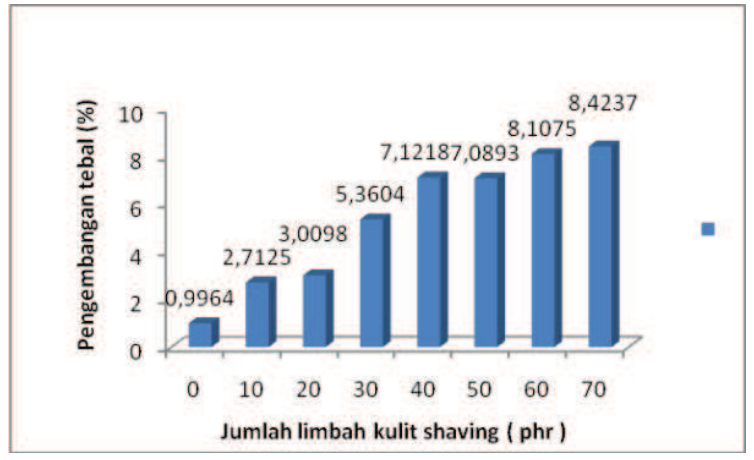

Gambar 6 : Pengembangan tebal papan partikel PVC dengan limbah kulit shaving

Hal ini disebabkan karena limbah padat industri penyamakan kulit (shaving) mempunyai molekul-molekul yang dapat menyerap air, sehingga makin banyak yang ditambahkan, nilai pengembangan tebal makin naik. Data pengembangan tebal untuk semua variasi papan partikel yang dicoba memperlihatkan bahwa hasilnya memenuhi persyaratan yang ditetapkan dalam SNI 032105-2006 Mutu Papan Partikel (pengembangan tebal maksimum 12\%). Dibandingkan dengan penelitian sebelumnya (Subiyanto $d k k, 2004$ ) yaitu papan partikel tandan kosong kelapa sawit (TKKS) dengan perekat $\mathrm{PF}$, menghasilkan pengembangan tebal yang lebih besar, sehingga tidak memenuhi persyaratan standar. Pengembangan tebal papan partikel yang dibuat dari serat alam TKKS dan serat lainnya kebanyakan tidak memenuhi standar, termasuk papan partikel dari serat sisal (Munawar dkk, 2004). Pengembangan tebal yang tidak dapat tercapai, kemungkinan disebabkan perekat hanya menempel pada permukaan serat (pada waktu proses pembuatan), sehingga tidak bisa menembus ke dalam serat karena kerasnya permukaan serat. Oleh karena itu pada waktu direndam air, air masih bisa masuk melalui ujung-ujung serat ke arah memanjang serat, sehingga menyebabkan pengembangan tebal papan yang besar. Hal tersebut tidak terjadi pada pembuatan papan partikel dengan limbah kulit shaving dan plastik PVC, karena papan partikel ini mempunyai kerapatan massa 
cukup tinggi.

\section{KESIMPULAN}

Penambahan limbah padat industri penyamakan kulit (shaving) pada kompon polyvinyl chloride untuk papan partikel, berpengaruh nyata menaikkan sifat kuat tarik, kadar air,dan pengembangan tebal, tapi menurunkan sifat kuat pegang sekrup, dan kuat lentur. Penambahan limbah kulit shaving tidak berpengaruh pada sifat kerapatan massa. Kompon hasil penelitian tidak dapat memenuhi persyaratan SNI 03-2105-2006 Mutu Papan Partikel pada hasil uji kerapatan massa dan kuat lentur. Papan partikel yang dapat memenuhi persyaratan standar selain kedua sifat tersebut adalah papan partikel dengan penambahan limbah maksimum 40 phr. Papan partikel tersebut mempunyai nilai kuat tarik $8,5 \mathrm{~kg} / \mathrm{cm}^{2}$, kuat pegang sekrup 33 $\mathrm{kg} / \mathrm{cm}^{2}$, kuat lentur $88,06 \mathrm{~kg} / \mathrm{cm}^{2}$, kadar air $3,1105 \%$, kerapatan massa $1,0923 \mathrm{~g} / \mathrm{cm}^{3}$, dan pengembangan tebal $7,1218 \%$.

\section{DAFTAR PUSTAKA}

Bambang Subiyanto, Subyakto, Sudijono, Mohamad Gopar, Entang Rasyid dan Sasa Sofyan Munawar, 2005. Pembuatan Papan Partikel Berukuran Komersial dari Limbah Tandan Kosong Kelapa Sawit dengan Perekat Urea Formaldehida. J. Ilmu \& Teknologi Kayu Tropis Vol. 3. No.1.

Blinn, C.R., Sinclair, S.A., Gallagher, L.B., Wengert, E.M., Christ, J.B., 1986. Economic Feasibility and Market Potential for Producing YellowPopulair Oriented Strand Board in the Appalachians, Forest Product Journal 36 (9), p. 40-44.
Blomquist, R.F., Chistiansen, A.W. and Gillespie, G.E., 1983. Adhesive Bonding of Woods and Other Structural Materials. The Pensylvania State University, New York.p. 391-393.

Gupta, R.K., 1983. Handbook of Small Scale Plastic Industries Small Business Publications, Roop Nagar, New Delhi.

Lasino dan Kusmara, D., 2000. Penelitian Pembuatan Papan Komposit dari Serbuk Kayu dan PVC, Journal Penelitian Permukiman, Vol.16. No.2. hal.2-9. Puslitbang Teknologi Permukiman, Badan Litbang Kimpraswil.

Munawar, S.S., B. Subiyanto., Subyakto and L. Suryanegara. 2004. Development of Panel Product from Natural Fiber of Sisal (Agave sisalana). Proceedings of the fifth International Wood Science Symposium, Kyoto, Japan, pp. 367-369.

SNI 03-2105-2006 Mutu Papan Partikel, Badan Standarisasi Nasional, Jakarta.

Subiyanto, B., Subyakto, Sudijono, M. Gopar dan S.S. Munawar, 2004. Pemanfaatan Limbah Tandan Kosong dari Industri Pengolahan Kelapa Sawit untuk Papan Partikel dengan Perekat Penol Formaldehida. Jurnal Ilmu dan Teknologi Kayu, Vol. 2 (2): 99-102. Masyarakat Peneliti Kayu Indonesia. Bogor.

Sutrisno, Yusuf Sudo Hadi, Paribotro Sutigno, dan Budi Prihanto, 2000. Hubungan antara Keteguhan Geser Tekan dengan Keteguhan Rekat Internal Papan Partikel. Journal Penelitian Permukiman, Vol.16. No.4. 